\title{
The role of the lateral hypothalamus and orexin in ingestive behavior: a model for the translation of past experience and sensed deficits into motivated behaviors
}

\author{
Seth W. Hurley ${ }^{1}$ and Alan Kim Johnson 1,2,3,4 * \\ 1 Department of Psychology, University of lowa, lowa City, IA, USA \\ ${ }^{2}$ Department of Pharmacology, University of lowa, lowa City, IA, USA \\ ${ }^{3}$ Department of Health and Human Physiology, University of lowa, lowa City, IA, USA \\ ${ }^{4}$ François M. Abboud Cardiovascular Center, University of lowa, lowa City, IA, USA
}

\section{Edited by:}

Arshad M. Khan, University of Texas at EI Paso, USA

\section{Reviewed by:}

Brian J. Oldfield, Monash

University, Australia

Susanne E. La Fleur, University of

Amsterdam, Netherlands

W. K. Samson, Saint Louis

University, USA

*Correspondence:

Alan Kim Johnson, Department of Psychology, University of lowa, 11 Seashore Hall E, lowa City, IA 52242, USA

e-mail: alan-johnson@uiowa.edu
The hypothalamus has been recognized for its involvement in both maintaining homeostasis and mediating motivated behaviors. The present article discusses a region of the hypothalamus known as the lateral hypothalamic area (LHA). It is proposed that brain nuclei within the LHA including the dorsal region of the lateral hypothalamus (LHAd) and perifornical area (PeF) provide a link between neural systems that regulate homeostasis and those that mediate appetitive motivated behaviors. Functional and immunohistochemical data indicate that the LHA promotes many motivated behaviors including food intake, water intake, salt intake, and sexual behavior. Anatomical tracing experiments demonstrate that the LHA is positioned to receive inputs from brain areas involved in regulating body fluid and energy homeostasis. Regions within the LHA send dense projections to the ventral tegmental area (VTA), providing a pathway for the LHA to influence dopaminergic systems generally recognized to be involved in motivated behaviors and their reinforcement. Furthermore, the LHA contains neurons that synthesize orexin/hypocretin, a neuropeptide that promotes many appetitive motivated behaviors. The LHA also receives inputs from brain areas involved in reward-related learning and orexin neuron activation can become conditioned to environmental stimuli that are associated with rewards. Therefore, it is hypothesized that the LHA integrates signaling from areas that regulate body fluid and energy balance and reward-related learning. In turn, this information is "fed into" mesolimbic circuitry to influence the performance of motivated behaviors. This hypothesis may foster experiments that will result in an improved understanding of LHA function. An improved understanding of LHA function may aid in treating disorders that are associated with an excess or impairment in the expression of ingestive behavior including obesity, anorexia, impairments in thirst, salt gluttony, and salt deficiency.

Keywords: motivation, homeostasis, lateral hypothalamus, neural plasticity, salt appetite, thirst, food intake, orexin

\section{INTRODUCTION}

In order to survive animals must maintain energy and fluid homeostasis. Calories are continually lost through processes that maintain basic life functions and as a result of behaving. Similarly, terrestrial animals continually lose water and sodium to the environment due to normal physiological and environmental processes including respiration, transpiration, perspiration, urination, and defecation. Some less-common circumstances pose a significant threat to both energy and body fluid homeostasis. For example, sicknesses can evoke states of hypophagia coupled with diarrhea and vomiting that deplete the body of water and sodium. Once the body has become deficient in calories, water, or sodium it is critical for an animal to seek out and ingest substances in the environment to restore homeostasis.

The central nervous system generates motivational states to promote the seeking and ingestion of substances in the environment. The motivational state of hunger, or the seeking and ingestion of food, is necessary for an animal to restore deficits in energy homeostasis. Thirst and sodium appetite (also known as [AKA] salt appetite), or the acquisition and consumption of water and sodium, are necessary to restore fluid balance. These motivated states are accompanied by central nervous system processes that energize behavior (i.e., produce a state of psychological arousal and encourage locomotor behavior) and promote goal directed behavior (Bindra, 1959; 
Bolles, 1975). It has been demonstrated that many motivational states are accompanied by a hedonic shift where the pleasurable or aversive responses evoked by specific stimuli are enhanced or inhibited (Garcia et al., 1974; Fanselow and Birk, 1982; Berridge et al., 1984; Mehiel and Bolles, 1988; Berridge and Schulkin, 1989). For example, when sodium-replete rats receive intra-oral infusions of hypertonic saline solutions they exhibit species-specific behavioral responses indicative of aversion (Grill and Norgren, 1978; Berridge et al., 1984) and sodiumreplete rats will generally eschew hypertonic saline solutions (Robinson and Berridge, 2013). However, when rats become sodium deficient they exhibit approach behaviors towards saline solutions and will perform responses that are instrumental to obtain sodium (AKA operant responses; Berridge et al., 1984; Clark and Bernstein, 2006; Robinson and Berridge, 2013). Under sodium deficient conditions they even display behavioral responses indicative of pleasure rather than aversion when hypertonic saline solutions are infused intra-orally (Berridge et al., 1984). Similarly, people rate salty foods as more palatable when they are sodium deficient (McCance, 1936; Beauchamp et al., 1990).

The motivated states of hunger, thirst, and salt appetite are strongly influenced by an animal's current state of energy and fluid balance (i.e., homeostatic state). It is reasonable to conceptualize the neural apparatus that monitor energy and fluid homeostasis as sensory systems in their own right. With respect to energy balance, the arcuate nucleus of the hypothalamus $(\mathrm{ARH})$ has received significant attention for its role in sensing peripheral signals related to hunger and satiety (Schwartz et al., 2000). An ensemble of forebrain nuclei lying along the lamina terminalis (LT) are important for detecting signals related to body fluid status (Denton et al., 1996; Johnson and Thunhorst, 1997). The specific structures along the LT are the subfornical organ (SFO), median preoptic area (MnPO), and organum vasculosum of the lamina terminalis (OVLT). To facilitate exposition these structures are collectively referred to as the LT. The SFO and OVLT are sensory circumventricular organs, or brain areas that lack a true blood-brain barrier (Johnson and Gross, 1993) which allows them to monitor substances in the blood that act as indicators of body fluid status (Johnson and Thunhorst, 1997, 2007). It is also worth noting here that there is currently debate as to whether the ARH lacks a blood-brain barrier and is a true circumventricular organ (Mimee et al., 2013). As such, it has been proposed that the LT may also function to detect signals related to energy balance (Mimee et al., 2013; Smith and Ferguson, 2014).

It is important to realize that the ingestion of food, water, and sodium require coordinated activity between neural circuits that sense energy and fluid status and the neural circuitry involved in mobilizing motivated behaviors (Garcia et al., 1974; Roitman et al., 1997; Kelley and Berridge, 2002; Liedtke et al., 2011). Therefore, the brain areas that monitor fluid and energy status must be able to project onto the areas that regulate motivation and reward. One final common pathway that is implicated in the generation of all appetitive motivated behaviors investigated thus far is the dopaminergic projection from the ventral tegmental area (VTA) to the nucleus accumbens (AKA the mesolimbic dopamine system and the A10 dopaminergic cell group; Mogenson et al., 1980; Bozarth, 1994). The ARH and the LT, which are involved in sensing energy and fluid balance, do not appear to directly innervate the VTA (Phillipson, 1979; Geisler and Zahm, 2005; however the ARH does directly project to the nucleus accumbens; Yi et al., 2006; van den Heuvel et al., 2014). As there are no direct projections to the VTA it is likely that areas in the hypothalamus may aid in "bridging the gap" between homeostasis and motivation and reward systems (Mogenson et al., 1980; Swanson and Mogenson, 1981; Swanson and Lind, 1986). For example, retrograde tracing studies have shown that a large region of the hypothalamus contains neurons that project to the VTA (Geisler and Zahm, 2005). This region extends from the dorsomedial hypothalamus $(\mathrm{DMH})$ to the dorsal region of the lateral hypothalamus (LHAd) and appears to be present across the entire anterior-posterior extent of the hypothalamus.

\section{THE EVIDENCE SUPPORTING A ROLE FOR THE LHA IN INTEGRATING HOMEOSTATIC STATE WITH MOTIVATION AND REWARD SYSTEMS}

In a classic paper, Stellar (1954) proposed a hypothalamuscentered theory of motivation. Stellar theorized that the hypothalamus contained anatomically dissociable "centers" and each center played a critical role in the promotion of specific motivated behaviors. For example, he posited that the hypothalamus contained centers that specifically control sex, satiety, hunger, and sleep. Stellar's proposal received careful experimental scrutiny and was found to be inadequate to explain emerging data (Miller et al., 1964; Miller, 1965; Hoebel and Teitelbaum, 1966; Booth et al., 1969). Despite the fact that Stellar's theory fell short of elucidating the role of the hypothalamus in specific motivated behaviors, considerable evidence now suggests that areas within the hypothalamus do, in fact, play an important role in promoting appetitive motivated behaviors in general.

Classic experiments that employed short bursts of electrical stimulation directed at the lateral hypothalamic area (LHA) demonstrated that the LHA is involved in motivation and reward processes. Olds and Milner (1954) originally found that rats will perform an operant to obtain acute electrical stimulation of the LHA, an experimental paradigm sometimes referred to as self-stimulation or brain stimulation reward. They interpreted their finding to mean that electrical stimulation of the LHA was rewarding (i.e., LHA stimulation evoked a subjective state of pleasure). If this assessment is correct, it would suggest that some neurons within the LHA are functionally important for coding pleasure from the consumption of rewards. However, others have suggested LHA stimulation may actually produce a subjective state of craving rather than pleasure per se (Berridge and Valenstein, 1991). If this interpretation is true it would suggest that a subset of neurons located in the LHAd are involved in the craving that drives animals to seek rewards. It is likely that the motivational and rewarding properties of LHA stimulation are the result of the activation of neurons in the LHA that project to the mesolimbic dopamine system (Phillipson, 1979; Geisler and Zahm, 2005). Recent experiments utilizing anatomical mapping 
of "hedonic hotspots", or brain areas that appear to code pleasure (Peciña and Berridge, 2000), show that neurons located in the anterior LHA project to a hedonic hotspot in the dorsomedial nucleus accumbens shell (Thompson and Swanson, 2010), and it is possible that LHA stimulation may activate these projection neurons to evoke a sensation of pleasure. Interestingly, if the LHA is stimulated for sufficient intervals $(\sim 10-30$ s) rats will perform motivated behaviors including drinking, eating, and copulatory behaviors (Wise, 1968). Furthermore, lesions of the LHA abolish food and water intake, copulation, and impair or abolish sodium appetite (Anand and Brobeck, 1951; Montemurro and Stevenson, 1957; Teitelbaum and Epstein, 1962; Wolf, 1964; Wolf and Quartermain, 1967; Cagguila et al., 1973; Grossman et al., 1978; Hansen et al., 1982).

Disruptions in energy or fluid balance alter responding for self-stimulation (Olds, 1958; Morris et al., 2006, 2010). Olds (1958) originally found that food-depriving rats and inducing the motivational state of hunger increased responding for self-stimulation. Furthermore, increased responding for selfstimulation during food deprivation can be prevented by administration of leptin, a hormone that promotes satiety (Fulton et al., 2000). In contrast to food deprivation, sodium depletion reduces responding for self-stimulation (Morris et al., 2010). Reduced responding for self-stimulation is even observed when rats are made salt hungry through administration of an exogenous hormone that promotes salt appetite; despite the fact rats maintain sodium balance during this treatment (Morris et al., 2006). It is unclear as to why the motivational states of hunger and salt appetite produce opposite effects on self-stimulation. However, these studies demonstrate that hunger and salt appetite alter selfstimulation responding and this effect appears to be independent of actual disruptions in energy or fluid homeostasis. For example, leptin normalizes self-stimulation responding without correcting lost calories (Fulton et al., 2000) and self-stimulation responding can be decreased through manipulations that evoke salt hunger without actually inducing a sodium deficit (Morris et al., 2006). Importantly, these experiments support the present hypothesis by showing that the LHA is sensitive to an animal's motivational state.

Some of the strongest evidence supporting a role for the hypothalamus in promoting motivated behavior comes from studies examining orexin (AKA hypocretin). Orexin is a neuropeptide that is expressed primarily in the caudal half of the hypothalamus where it is distributed in an arc that extends from the DMH to the LHAd (Figure 1). Orexin appears to be the only known centralized peptide neurotransmitter system as orexin neurons from a relatively circumscribed area send distal projections to diverse brain areas (Peyron et al., 1998). Functionally, orexin neurons have been heavily implicated in a variety of motivated behaviors (Harris et al., 2005; Borgland et al., 2009). Orexin has received significant attention for its capacity to elicit robust food intake (hence the name orexin; Sakurai et al., 1998; Choi et al., 2010) but it is also involved in promoting thirst, salt appetite (Kunii et al., 1999; Hurley et al., 2013a), and reproductive behavior (Muschamp et al., 2007; Di Sebastiano et al., 2010). Orexin neurons can be putatively organized into three cell-clusters in the hypothalamus: a cluster in the $\mathrm{DMH}$, perifornical area (PeF), and the LHAd (Figure 1). Both the PeF and LHAd are regions located in the LHA while the DMH lies medially where it abuts the third ventricle. Each orexin cellcluster contains a subset of orexin neurons that project to the VTA (Figure 1; Fadel and Deutch, 2002), and orexin is capable of depolarizing neurons in the VTA (Korotkova et al., 2003). Therefore, orexin neurons provide a mechanism for areas within the LHA to tap into systems traditionally conceived of as being involved in motivation and reward. Evidence also indicates that orexin neurons have direct projections to the nucleus accumbens shell (Peyron et al., 1998; Kampe et al., 2009) where they may act to promote motivated behaviors (Thorpe and Kotz, 2005).

Other major functions of orexin include promoting arousal (Hagan et al., 1999) and sympathetic nervous system responses including the elevation of blood pressure (Samson et al., 1999; Ferguson and Samson, 2003; Kayaba et al., 2003) and the release of stress hormones (Kuru et al., 2000; Spinazzi et al., 2006). It is likely that orexin neurons are activated while an animal is experiencing caloric, hydrational, or sodium deficiency or is in a state of sexual arousal. The subsequent release of orexin throughout the neuraxis encourages the performance of goal-directed behavior by activating brain systems involved in promoting arousal, attention, sympathetic activity, and motivated behavior. Sympathetic activation supports energy mobilization (e.g., increased blood pressure and available glucose levels, and stress hormone release) as well as the redistribution of blood necessary to support increased locomotor activity. Together these central and peripheral responses serve to increase the likelihood that an animal will successfully seek out and consume environmental reinforcers that restore energy and hydrational homeostasis.

Anatomical and immunohistochemical studies support the idea that the LHA aids in integrating signaling from orexigenic peptides with neurocircuitry involved in motivation and reward. Neuropeptide Y (NPY) is expressed in ARH neurons (Hahn et al., 1998) and this neuropeptide induces feeding (Schwartz et al., 2000). Interestingly, NPY neurons send dense projections that are in apposition with orexin neurons located in the LHA (Broberger et al., 1998). Treatments that induce hunger such as hypoglycemia or administration of orexigenic peptides including ghrelin and NPY induce c-fos expression in orexin-containing neurons (Moriguchi et al., 1999; Niimi et al., 2001; Toshinai et al., 2003). Additionally, compromising orexin neurotransmission attenuates feeding induced by administration of either NPY or ghrelin. Neurons in the dorsomedial ARH, a region of the ARH that contains a majority of NPY neurons, also project to the PeF and possibly the LHAd (Figure 2; Hahn and Swanson, 2010).

In contrast to studies on food intake, relatively little work has been done delineating how the LT may influence motivation and reward neural circuitry. The LT does not appear to directly project to either the VTA (Phillipson, 1979; Geisler and Zahm, 2005) or the nucleus accumbens (Brog et al., 1993), but somehow areas sensing and processing information related to body fluid homeostasis must tap into motivation and reward neurocircuitry. The SFO has been shown to send projections to the DMH, PeF, and LHAd (Swanson and Lind, 1986; 


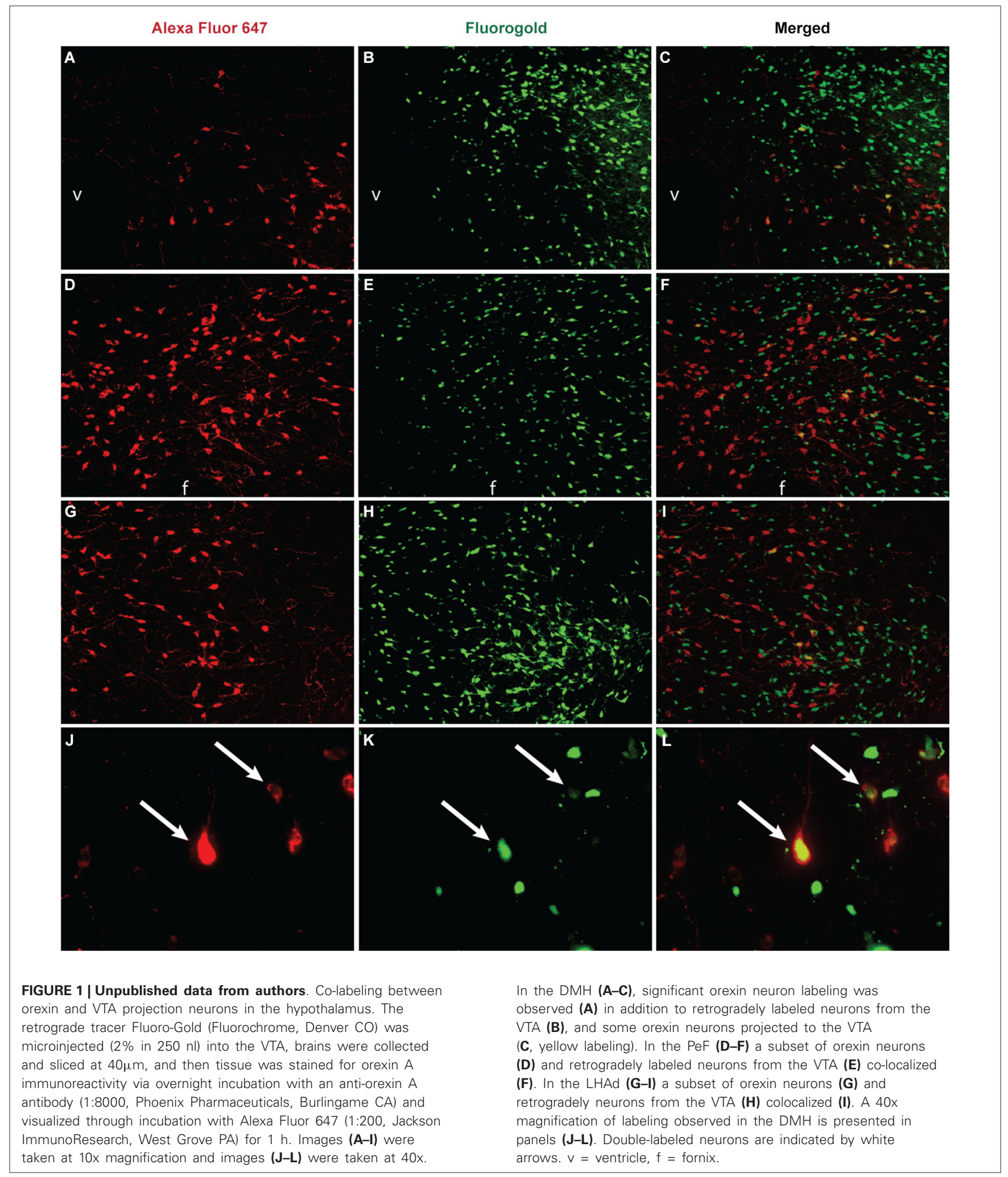

Hurley et al., 2013a). Furthermore, recent experiments in our laboratory have shown that iontophoretic application of the retrograde tracer Fluoro-Gold into the posterior portion of the
$\mathrm{DMH}, \mathrm{PeF}$, and LHAd reveals retrograde labeling across the entirety of the LT (an example of retrograde labeling from an injection that spread from the PeF to the $\mathrm{LH}$ is presented in 

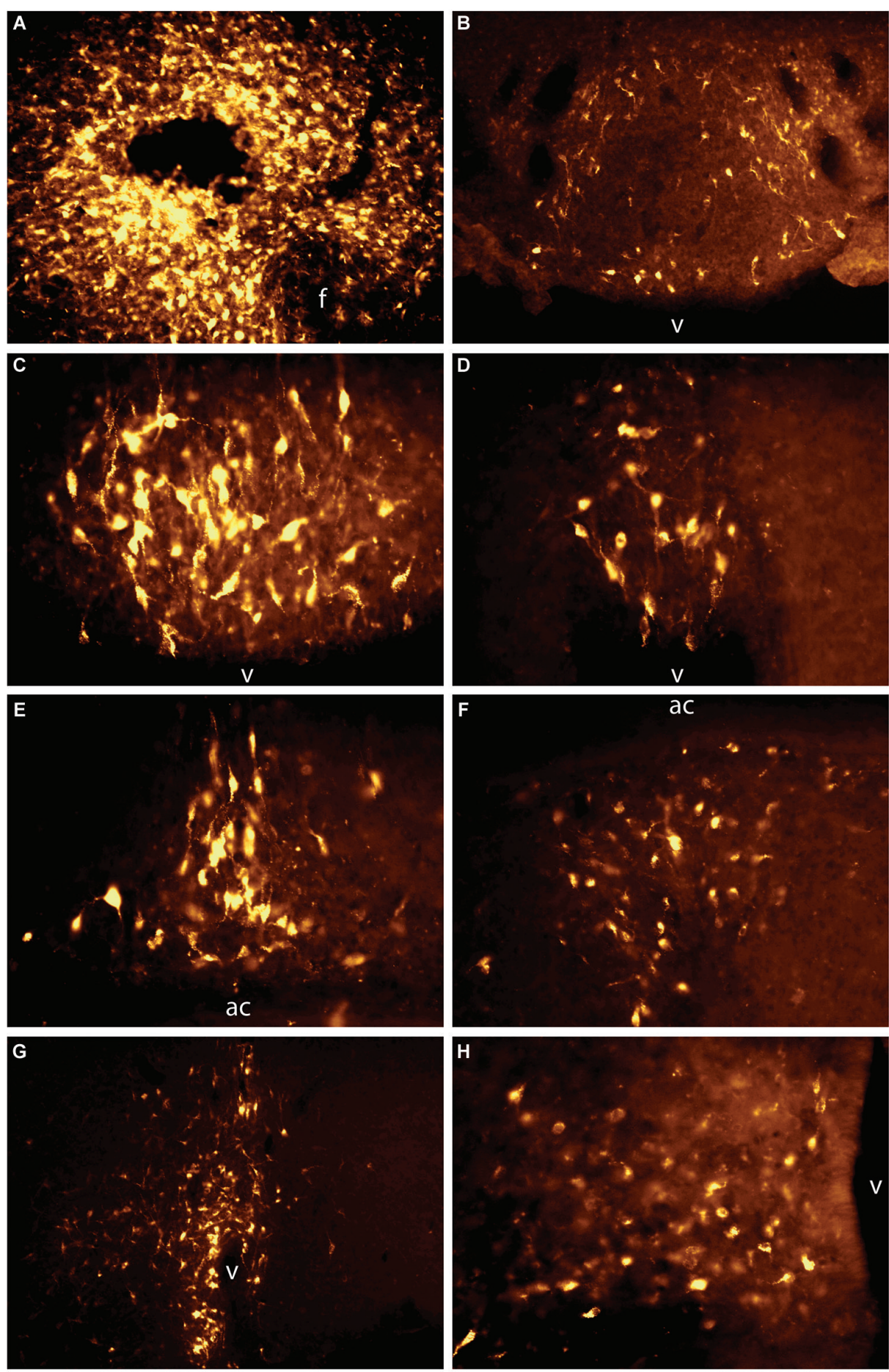

FIGURE 2 | Unpublished data from authors. Retrograde labeling from the LHAd and PeF to the LT and arcuate nucleus of the hypothalamus. $2 \%$ Fluoro-Gold in physiological saline was iontophoresed into the PeF and LHAd (A). Retrograde labeling was observed across the LT and in the ARH. Specifically, significant retrograde-labeling was seen in the annulus of the
SFO (B), anterior SFO (C), stalk of the SFO (D), dorsal and ventral MnPO $(\mathbf{E}, \mathbf{F}), \operatorname{OVLT}(\mathbf{G})$, and ARH (H). Images were taken at different magnifications to compensate for the size of the brain area. Panels $(\mathbf{A}),(\mathbf{B})$, and $(\mathbf{G})$ were taken at $10 x$ and (C), (D), (E), (F), and (H) were taken at 20x. $f=$ fornix, $v=$ ventricle, $\mathrm{ac}=$ anterior commissure.
Figure 2). Others have shown that the PeF receives projections from the entirety of the LT (Hahn and Swanson, 2010).
Additionally, we have recently found that orexin neurons are activated when rats depleted of water and sodium are allowed 
to ingest water and hypertonic saline and that microinjection of an orexin receptor antagonist into the VTA attenuated combined water and sodium intake in depleted rats (Hurley et al., 2013a). Therefore, it is likely that the LT projects to the DMH, PeF and LHAd which, in turn, send orexinergic projections to the VTA. Orexin release in the VTA promotes the ingestion of water and sodium. These experiments provide both anatomical and functional support to the hypothesis that the LHA integrates information about homeostatic state with motivation and reward systems.

\section{THE EVIDENCE SUPPORTING A ROLE FOR THE LHA IN REWARD-RELATED LEARNING}

Experiments that examined the effect of sustained LHA stimulation on motivated behaviors provided some of the earliest evidence that the LHA may be involved in reward-related learning. When individual rats receive LHA stimulation they initially exhibit one specific motivated behavior (Valenstein et al., 1970). Some rats will eat, while others will drink or engage in copulatory behaviors. The motivated behavior each rat engages in is referred to as the prepotent behavior. Importantly, the prepotent behavior performed during LHA stimulation can be modified by experience (Valenstein et al., 1970). If the preferred goal object is removed during LHA stimulation, rats will direct their motivated behavior towards another goal object that is present in the environment. For example, if a rat eats during LHA stimulation, food can be removed while a drinking spout remains. In this situation the stimulated rat will now drink from the spout. Importantly, when the LHA is stimulated in future trials when both food and water are present, the rat will essentially split its time between eating and drinking. Therefore, pairing LHA stimulation with the presence of an initially non-preferred goal object causes a rat to direct some of its behavior toward the previously ignored goal object. It appears that LHA stimulation and the subsequent consumption of a goal object results in a form of associative learning that is expressed through changes in prepotent behaviors.

Orexin neuron activation can also become conditioned to stimuli in the environment. In conditioned place preference paradigms a novel environmental context is associated with a reward. After repeated pairings of an environmental context with a reward, rats will exhibit a preference for the context that was paired with reward. The preference that develops in conditioned place preference paradigms appears to be associated with orexin neuron activation. Orexin neurons express c-fos in response to environmental contexts that have become associated with drugs of abuse and sex (Harris et al., 2005; Di Sebastiano et al., 2011). Furthermore, lesioning orexin neurons with an orexin conjugated-saporin prevents male rats from exhibiting a conditioned place preference for an environmental context associated with copulation (Di Sebastiano et al., 2011).

Further evidence supporting LHA involvement in associative forms of reward learning comes from the phenomenon of cue-induced feeding. In the cue-induced feeding paradigm, food-deprived rats are allowed to eat in the presence of an environmental cue. This cue essentially becomes a conditioned stimulus ( $\mathrm{CS}+$ ) that is capable of inducing food intake. When the $\mathrm{CS}+$ is presented to rats, even when they are in a satiated state, they will begin eating (Petrovich et al., 2007). Interestingly, rats will only ingest significant quantities of the specific food paired with the CS+, but not novel or familiar foods (Petrovich and Gallagher, 2007). Therefore, it appears that presentation of the CS+ evokes a specific craving for the food paired with the CS+, rather than hunger per se. The LHA is one area that is critical for the performance of cue-induced feeding (Petrovich and Gallagher, 2007; Petrovich et al., 2005). The LHA receives inputs from areas involved in associative forms of reward-learning including the amygdala (Krettek and Price, 1978; Everitt et al., 1999) and prefrontal cortex (Gallagher et al., 1999). Neurons that project to the LHA from the basolateral/basomedial amygdala and orbitomedial prefrontal cortex are activated in response to presentation of the CS+ (Petrovich et al., 2005). In addition, contralateral asymmetrical lesions of the basolateral amygdala and LHA prevent cue-induced feeding (Petrovich et al., 2005). Orexin also appears to plays a role in cue-induced feeding as rats exposed to the CS+ express significantly more c-fos positive orexin neurons in the PeF (Petrovich et al., 2012).

Finally, the LHA has been implicated in non-associative forms of reward-related learning. When rats are repeatedly depleted of sodium they exhibit an increase in sodium intake (Falk, 1965; Sakai et al., 1987, 1989), a phenomenon termed the sensitization of sodium appetite (Hurley et al., 2013b). Sensitization of sodium appetite is likely to be a form of nonassociative learning (Falk, 1966; Frankmann et al., 1986) that is dependent on glutamatergic NMDA receptor-dependent neural plasticity (Hurley and Johnson, 2013). Evidence suggests that sodium appetite sensitization involves neural plasticity in two neural circuits: one circuit governing body fluid homeostasis and another circuit mediating motivation and reward (Roitman et al., 2002; Na et al., 2007). c-fos expression induced by sodium depletion is elevated in rats with a history of sodium depletions in the SFO, basolateral amygdala, medial prefrontal cortex, and nucleus accumbens compared to rats with no history of sodium depletions (Na et al., 2007). Furthermore, rats with a history of sodium depletions exhibit enhanced dendritic arborization and length in the nucleus accumbens (Roitman et al., 2002). Many of the areas that appear to undergo sensitization during sodium depletion also send projections to the LHA, including the SFO, prefrontal cortex, and basolateral amygdala. The LHA sends projections to the VTA, which in turn is capable of inducing neural plasticity in nucleus accumbens neurons (Mameli et al., 2009). Finally, additional evidence supports the possibility that orexin neurons undergo neural plasticity from sodium depletion (Liedtke et al., 2011). Activity-regulated cytoskeleton-associated protein, which plays a critical role in neural plasticity (Tzingounis and Nicoll, 2006; Shepherd and Bear, 2011), is upregulated in PeF orexin neurons during sodium depletion (Liedtke et al., 2011).

\section{SYNTHESIS AND CONCLUSIONS}

The reviewed experiments support the hypothesis that the LHA contributes to the integration of information related to homeostatic state and past experience with motivation and reward systems. A summary of the anatomical and functional data is presented in Figure 3. Nuclei within the LHA, including the PeF and LHAd, receive projections from brain areas that regulate energy and body fluid homeostasis in addition to areas involved 


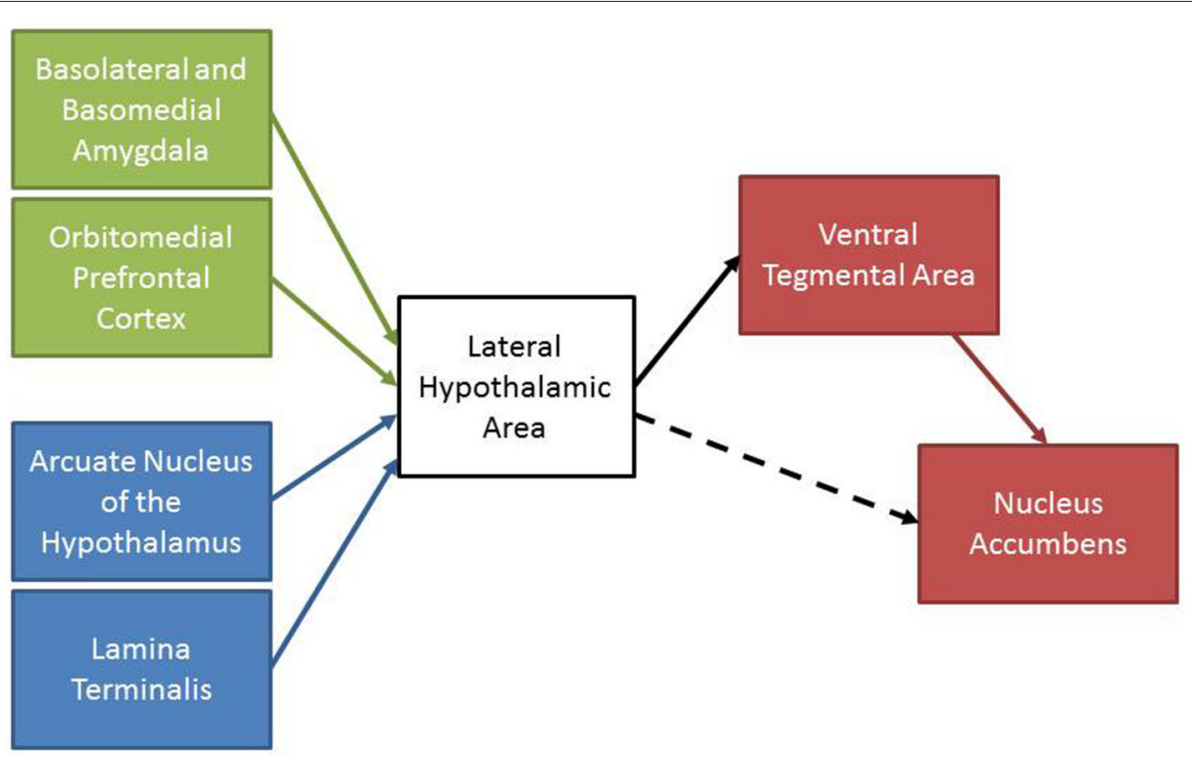

FIGURE 3 | A schematic summary of the reviewed experiments. Areas involved in associative learning (green) and maintaining homeostasis (blue) project to the LHA. The LHA sends projections to motivation and reward areas (red) to initiate motivated behaviors. The LHA also sends projections to the nucleus accumbens that may promote motivated behaviors (dashed line). in associative learning (Broberger et al., 1998; Petrovich et al., 2005; Hurley et al., 2013a). In turn, these areas of the LHA send projections to the VTA where they promote motivated behaviors, at least partially through the release of orexin in the VTA (Phillipson, 1979; Fadel and Deutch, 2002; Geisler and Zahm, 2005). Although Figure 3 displays a hierarchical model of LHA functioning dominated by efferent connections to downstream brain areas, it may be the case that this circuitry is actually a neural network which consists of bidirectional inputs between areas involved in learning, homeostasis, and motivation and reward. In this respect, the use of anterograde and retrograde tracer co-injections would provide utility in identifying whether these areas form a neuronal network (for example see Thompson and Swanson, 2010).

As orexin is not exclusively involved in mediating just a single motivated behavior, it is likely that orexin acts to strengthen goal-directed responses associated with several motivated states (Borgland et al., 2009). Cues related to reward presentation and consumption can also induce activation of orexin neurons (Harris et al., 2005; Di Sebastiano et al., 2011; Petrovich et al., 2012), suggesting that past experience influences orexin neuron activity. Therefore, there are at least two conditions that induce orexin neuron activity: (1) the actual seeking and consumption of rewards; and (2) learned associations with rewards. With respect to the second point it is important to point out that orexin can induce neural plasticity in the VTA itself (Borgland et al., 2006). It is unlikely that orexin mediates all of the effects on motivated behaviors observed through manipulations of the LHA, as many projections from the hypothalamus to the VTA are non-orexinergic.

Future work that aims to carefully investigate the role of nuclei located within the LHA will prove fruitful. The LHA actually consists of a collection of heterogeneous brain areas that have unique neuroanatomical connections and cytoarchitecture (Swanson et al., 2005; Hahn and Swanson, 2010). Furthermore, it appears that separate orexin neuron clusters are activated under different experimental conditions (Harris et al., 2005; Harris and Aston-Jones, 2006; Petrovich et al., 2012). Optogenetic manipulations provide a method to test whether these orexin cell clusters have a functionally significant projection to the VTA or nucleus accumbens. Additionally, inactivation of orexin cell clusters should influence the activity of VTA and nucleus accumbens neurons. Finally, it is worth noting that many of the discussed experiments did not dissociate and define the roles of brain nuclei within the LHA and did not discuss the role of the $\mathrm{DMH}$ in motivated behaviors. The $\mathrm{DMH}$ also receives projections from body fluid homeostasis areas (Swanson and Lind, 1986), sends projections to the VTA (Geisler and Zahm, 2005), and contains orexin neurons (Fadel and Deutch, 2002), all of which are potentially involved in homeostatic behaviors.

\section{HEALTH IMPLICATIONS}

From a behavioral perspective, some disorders can be conceived of as problems of ingestion. For example, anorexics fail to ingest sufficient amounts of food while those suffering from obesity ingest too much food. Similarly, some individuals ingest far too much sodium; a phenomenon sometimes referred to as salt gluttony (Schulkin, 1986), while others ingest too little sodium and consequently become sodium deficient causing them to experience autonomic and cardiovascular dysfunction (Bou-Holaigah et al., 1995). Additionally, elderly individuals may exhibit diminished thirst and subsequent dehydration (Rolls and Phillips, 1990; Warren et al., 1994). One approach to understanding these maladies that are marked by a surplus or surfeit in ingestive behavior 
is to conceive of them as problems of central nervous system functioning related to maintaining homeostasis and appropriately engaging in motivated behavior. As the LHA is critically involved in both maintaining homeostasis and mediating motivated behaviors, an improved understanding of the LHA may aid in diagnosing and treating disorders of ingestion.

\section{ACKNOWLEDGMENTS}

The authors thank Young In Kim for her technical assistance and Marilyn Dennis for comments on the manuscript. This research was supported by National Institutes of Health grants HL14388, HL098207, and MH08241. The authors have no disclosures to report.

\section{REFERENCES}

Anand, B. K., and Brobeck, J. R. (1951). Hypothalamic control of food intake in rats and cats. Yale J. Biol. Med. 24, 123-140.

Beauchamp, G. K., Bertino, M., Burke, D., and Engelman, K. (1990). Experimental sodium depletion and salt taste in normal human volunteers. Am. J. Clin. Nutr. 51, 881-889.

Berridge, K. C., Flynn, F. W., Schulkin, J., and Grill, H. J. (1984). Sodium depletion enhances salt palatability in rats. Behav. Neurosci. 98, 652-660. doi: 10 . 1037//0735-7044.98.4.652

Berridge, K. C., and Schulkin, J. (1989). Palatability shift of a salt-associated incentive during sodium depletion. Q. J. Exp. Psychol. B 41, 121-138.

Berridge, K. C., and Valenstein, E. S. (1991). What psychological process mediates feeding evoked by electrical stimulation of the lateral hypothalamus? Behav. Neurosci. 105, 3-14. doi: 10.1037//0735-7044.105.1.3

Bindra, D. (1959). Motivation: A Systematic Reinterpretation. New York, NY: John Wiley and Sons.

Bolles, R. C. (1975). Theory of Motivation. 2 Edn., New York: Harper and Row.

Booth, D. A., Coons, E. E., and Miller, N. E. (1969). Blood glucose responses to electrical stimulation of the hypothalamic feeding area. Physiol. Behav. 4, 9911001. doi: 10.1016/0031-9384(69)90055-9

Borgland, S. L., Chang, S. J., Bowers, M. S., Thompson, J. L., Vittoz, N., Floresco, S. B., et al. (2009). Orexin A/hypocretin-1 selectively promotes motivation for positive reinforcers. J. Neurosci. 29, 11215-11225. doi: 10.1523/jneurosci.609608.2009

Borgland, S. L., Taha, S. A., Sarti, F., Fields, H. L., and Bonci, A. (2006). Orexin $\mathrm{A}$ in the VTA is critical for the induction of synaptic plasticity and behavioral sensitization to cocaine. Neuron 49, 589-601. doi: 10.1016/j.neuron.2006.01.016

Bou-Holaigah, I., Rowe, P. C., Kan, J., and Calkins, H. (1995). The relationship between neurally mediated hypotension and the chronic fatigue syndrome. JAMA 274, 961-967. doi: 10.1001/jama.274.12.961

Bozarth, M. A. (1994). "Pleasure systems in the brain," in Pleasure: The Politics and the Reality, ed D. M. Warburton (New York, NY: John Wiley and Sons), 5-14.

Broberger, C., De Lecea, L., Sutcliffe, J., and Hökfelt, T. (1998). Hypocretin/orexinand melanin-concentrating hormone-expressing cells form distinct populations in the rodent lateral hypothalamus: relationship to the neuropeptide $\mathrm{Y}$ and agouti gene-related protein systems. J. Comp. Neurol. 402, 460-474. doi: 10. 1002/(sici)1096-9861(19981228)402:4<460::aid-cne3>3.3.co;2-j

Brog, J. S., Salyapongse, A., Deutch, A. Y., and Zahm, D. S. (1993). The patterns of afferent innervation of the core and shell in the "Accumbens" part of the rat ventral striatum: immunohistochemical detection of retrogradely transported fluoro gold. J. Comp. Neurol. 338, 255-278. doi: 10.1002/cne.903380209

Cagguila, A. R., Antelman, S. M., and Zigmond, M. J. (1973). Disruption of copulation in male rats after hypothalamic lesions: a behavioral, anatomical and neurochemical analysis. Brain Res. 59, 273-287. doi: 10.1016/00068993(73)90266-7

Choi, D., Davis, J., Fitzgerald, M., and Benoit, S. (2010). The role of orexin-A in food motivation, reward-based feeding behavior and food-induced neuronal activation in rats. Neuroscience 167, 11-20. doi: 10.1016/j.neuroscience.2010. 02.002

Clark, J. J., and Bernstein, I. L. (2006). Sensitization of salt appetite is associated with increased "wanting" but not "liking" of a salt reward in the sodium-deplete rat. Behav. Neurosci. 120, 206-210. doi: 10.1037/0735-7044.120.1.206
Denton, D. A., McKinley, M. J., and Weisinger, R. S. (1996). Hypothalamic integration of body fluid regulation. Proc. Natl. Acad. Sci. U S A 93, 7397-7404. doi: $10.1073 /$ pnas.93.14.7397

Di Sebastiano, A. R., Wilson-Pérez, H. E., Lehman, M. N., and Coolen, L. M. (2011). Lesions of orexin neurons block conditioned place preference for sexual behavior in male rats. Horm. Behav. 59, 1-8. doi: 10.1016/j.yhbeh.2010.09.006

Di Sebastiano, A. R., Yong-Yow, S., Wagner, L., Lehman, M. N., and Coolen, L. M. (2010). Orexin mediates initiation of sexual behavior in sexually naive male rats, but is not critical for sexual performance. Horm. Behav. 58, 397-404. doi: 10 . 1016/j.yhbeh.2010.06.004

Everitt, B. J., Parkinson, J. A., Olmstead, M. C., Arroyo, M., Robledo, P., and Robbins, T. W. (1999). Associative processes in addiction and reward the role of amygdala-ventral striatal subsystems. Ann. N Y Acad. Sci. 877, 412-438. doi: 10. 1111/j.1749-6632.1999.tb09280.x

Fadel, J., and Deutch, A. (2002). Anatomical substrates of orexin-dopamine interactions: lateral hypothalamic projections to the ventral tegmental area. Neuroscience 111, 379-387. doi: 10.1016/s0306-4522(02)00017-9

Falk, J. L. (1965). Water intake and $\mathrm{NaCl}$ appetite in sodium depletion. Psychol. Rep. 16, 315-325. doi: 10.2466/pr0.1965.16.1.315

Falk, J. L. (1966). Serial sodium depletion and NaCl solution intake. Physiol. Behav. 1, 75-77. doi: 10.1016/0031-9384(66)90044-8

Fanselow, M. S., and Birk, J. (1982). Flavor-flavor associations induce hedonic shifts in taste preference. Anim. Learn. Behav. 10, 223-228. doi: 10.3758/bf03212274

Ferguson, A. V., and Samson, W. K. (2003). The orexin/hypocretin system: a critical regulator of neuroendocrine and autonomic function. Front. Neuroendocrinol. 24, 141-150. doi: 10.1016/s0091-3022(03)00028-1

Frankmann, S. P., Dorsa, D. M., Sakai, R. R., and Simpson, J. B. (1986). “A single experience with hyperoncotic colloid dialysis persistently alters water and sodium intake," in The Physiology of Thirst and Sodium Appetite, eds G. E. de Caro, A. N. Epstein and M. Massi (New York, NY: Plenum Press), 115-121.

Fulton, S., Woodside, B., and Shizgal, P. (2000). Modulation of brain reward circuitry by leptin. Science 287, 125-128. doi: 10.1126/science.287.5450.125

Gallagher, M., McMahan, R. W., and Schoenbaum, G. (1999). Orbitofrontal cortex and representation of incentive value in associative learning. J. Neurosci. 19, 6610-6614.

Garcia, J., Hankins, W. G., and Rusiniak, K. W. (1974). Behavioral regulation of the milieu interne in man and rat. Science 185, 824-831. doi: 10.1126/science.185. 4154.824

Geisler, S., and Zahm, D. S. (2005). Afferents of the ventral tegmental area in the rat-anatomical substratum for integrative functions. J. Comp. Neurol. 490, 270 294. doi: $10.1002 /$ cne. 20668

Grill, H. J., and Norgren, R. (1978). The taste reactivity test. I. Mimetic responses to gustatory stimuli in neurologically normal rats. Brain Res. 143, 263-279. doi: 10. 1016/0006-8993(78)90568-1

Grossman, S. P., Dacey, D., Halaris, A. E., Collier, T., and Routtenberg, A. (1978). Aphagia and adipsia after preferential destruction of nerve cell bodies in hypothalamus. Science 202, 537-539. doi: 10.1126/science.705344

Hagan, J. J., Leslie, R. A., Patel, S., Evans, M. L., Wattam, T. A., Holmes, S., et al. (1999). Orexin A activates locus coeruleus cell firing and increases arousal in the rat. Proc. Natl. Acad. Sci. U S A 96, 10911-10916. doi: 10.1073/pnas.96.19.10911

Hahn, T. M., Breininger, J. F., Baskin, D. G., and Schwartz, M. W. (1998). Coexpression of Agrp and NPY in fasting-activated hypothalamic neurons. Nat. Neurosci. $1,271-272$.

Hahn, J. D., and Swanson, L. W. (2010). Distinct patterns of neuronal inputs and outputs of the juxtaparaventricular and suprafornical regions of the lateral hypothalamic area in the male rat. Brain Res. Rev. 64, 14-103. doi: 10.1016/j. brainresrev.2010.02.002

Hansen, S., Goldstein, M., and Steinbusch, H. (1982). Effects of ibotenic acidinduced neuronal degeneration in the medial preoptic area and the lateral hypothalamic area on sexual behavior in the male rat. Brain Res. 239, 213-232. doi: 10.1016/0006-8993(82)90843-5

Harris, G. C., and Aston-Jones, G. (2006). Arousal and reward: a dichotomy in orexin function. Trends Neurosci. 29, 571-577. doi: 10.1016/j.tins.2006.08.002

Harris, G. C., Wimmer, M., and Aston-Jones, G. (2005). A role for lateral hypothalamic orexin neurons in reward seeking. Nature 437, 556-559. doi: 10. 1038/nature04071

Hoebel, B. G., and Teitelbaum, P. (1966). Weight regulation in normal and hypothalamic hyperphagic rats. J. Comp. Physiol. Psychol. 61, 189-193. doi: 10. 1037/h0023126 
Hurley, S. W., Arseth, H. A., and Johnson, A. K. (2013a). “A role for orexin neurons in water and sodium intake," in Society for Neuroscience (San Diego, CA).

Hurley, S. W., and Johnson, A. K. (2013). Dissociation of thirst and sodium appetite in the furo/cap model of extracellular dehydration and a role for N-methyl-Daspartate receptors in the sensitization of sodium appetite. Behav. Neurosci. 127, 890-898. doi: 10.1037/a0034948

Hurley, S. W., Thunhorst, R. L., and Johnson, A. K. (2013b). "Sodium appetite sensitization," in Neurobiology of Body Fluid Homeostasis: Transduction and Integration (Series IV: Frontiers in Neuroscience), eds L. A. De Luca, A. K. Johnson and J. V. Menani (Boca Raton, FL: Taylor and Francis), 279-301.

Johnson, A. K., and Gross, P. M. (1993). Sensory circumventricular organs and brain homeostatic pathways. FASEB J. 7, 678-686.

Johnson, A. K., and Thunhorst, R. L. (1997). The neuroendocrinology of thirst and salt appetite: visceral sensory signals and mechanisms of central integration. Front. Neuroendocrinol. 18, 292-353. doi: 10.1006/frne.1997.0153

Johnson, A., and Thunhorst, R. (2007). The neuroendocrinology, neurochemistry and molecular biology of thirst and salt appetite. Handb. Neurochem. Mol. Neurobiol. Behav. Neurochem. Neuroendocrinol. Mol. Neurobiol. 3, 641-687. doi: 10.1007/978-0-387-30405-2_17

Kampe, J., Tschöp, M. H., Hollis, J. H., and Oldfield, B. J. (2009). An anatomic basis for the communication of hypothalamic, cortical and mesolimbic circuitry in the regulation of energy balance. Eur. J. Neurosci. 30, 415-430. doi: 10.1111/j. 1460-9568.2009.06818.x

Kayaba, Y., Nakamura, A., Kasuya, Y., Ohuchi, T., Yanagisawa, M., Komuro, I., et al. (2003). Attenuated defense response and low basal blood pressure in orexin knockout mice. Am. J. Physiol. Regul. Integr. Comp. Physiol. 285, R581-R593. doi: 10.1152/ajpregu.00671.2002

Kelley, A. E., and Berridge, K. C. (2002). The neuroscience of natural rewards: relevance to addictive drugs. J. Neurosci. 22, 3306-3311.

Korotkova, T. M., Sergeeva, O. A., Eriksson, K. S., Haas, H. L., and Brown, R. E. (2003). Excitation of ventral tegmental area dopaminergic and nondopaminergic neurons by orexins/hypocretins. J. Neurosci. 23, 7-11.

Krettek, J. E., and Price, J. L. (1978). Amygdaloid projections to subcortical structures within the basal forebrain and brainstem in the rat and cat. J. Comp. Neurol. 178, 225-253. doi: 10.1002/cne.901780204

Kunii, K., Yamanaka, A., Nambu, T., Matsuzaki, I., Goto, K., and Sakurai, T. (1999). Orexins/hypocretins regulate drinking behaviour. Brain Res. 842, 256261. doi: 10.1016/s0006-8993(99)01884-3

Kuru, M., Ueta, Y., Serino, R., Nakazato, M., Yamamoto, Y., Shibuya, I., et al. (2000). Centrally administered orexin/hypocretin activates HPA axis in rats. Neuroreport 11, 1977-1980. doi: 10.1097/00001756-200006260-00034

Liedtke, W. B., McKinley, M. J., Walker, L. L., Zhang, H., Pfenning, A. R., Drago, J., et al. (2011). Relation of addiction genes to hypothalamic gene changes subserving genesis and gratification of a classic instinct, sodium appetite. Proc. Natl. Acad. Sci. U S A 108, 12509-12514. doi: 10.1073/pnas.1109199108

Mameli, M., Halbout, B., Creton, C., Engblom, D., Parkitna, J. R., Spanagel, R., et al. (2009). Cocaine-evoked synaptic plasticity: persistence in the VTA triggers adaptations in the NAc. Nat. Neurosci. 12, 1036-1041. doi: 10.1038/nn.2367

McCance, R. A. (1936). Experimental sodium chloride deficiency in man. Proc. $R$. Soc. Lond. B Biol. Sci. 119, 245-268. doi: 10.1098/rspb.1936.0009

Mehiel, R., and Bolles, R. C. (1988). Hedonic shift learning based on calories. Bull. Psychon. Soc. 26, 459-462. doi: 10.3758/bf03334913

Miller, N. E. (1965). Chemical coding of behavior in the brain. Science 148, 328338. doi: $10.1126 /$ science. 148.3668 .328

Miller, N. E., Gottesman, K. S., and Emery, N. (1964). Dose response to carbachol and norepinephrine in rat hypothalamus. Am. J. Physiol. 206, 1384-1388.

Mimee, A., Smith, P. M., and Ferguson, A. V. (2013). Circumventricular organs: targets for integration of circulating fluid and energy balance signals? Physiol. Behav. 121, 96-102. doi: 10.1016/j.physbeh.2013.02.012

Mogenson, G. J., Jones, D. L., and Yim, C. Y. (1980). From motivation to action: functional interface between the limbic system and the motor system. Prog. Neurobiol. 14, 69-97. doi: 10.1016/0301-0082(80)90018-0

Montemurro, D., and Stevenson, J. (1957). Adipsia produced by hypothalamic lesions in the rat. Can. J. Biochem. Physiol. 35, 31-37. doi: 10.1139/o57-005

Moriguchi, T., Sakurai, T., Nambu, T., Yanagisawa, M., and Goto, K. (1999). Neurons containing orexin in the lateral hypothalamic area of the adult rat brain are activated by insulin-induced acute hypoglycemia. Neurosci. Lett. 264, 101104. doi: 10.1016/s0304-3940(99)00177-9
Morris, M. J., Na, E. S., Grippo, A. J., and Johnson, A. K. (2006). The effects of deoxycorticosterone-induced sodium appetite on hedonic behaviors in the rat. Behav. Neurosci. 120, 571-578. doi: 10.1037/0735-7044.120.3.571

Morris, M. J., Na, E. S., and Johnson, A. K. (2010). Mineralocorticoid receptor antagonism prevents hedonic deficits induced by a chronic sodium appetite. Behav. Neurosci. 124, 211-224. doi: 10.1037/a0018910

Muschamp, J. W., Dominguez, J. M., Sato, S. M., Shen, R. Y., and Hull, E. M. (2007). A role for hypocretin (orexin) in male sexual behavior. J. Neurosci. 27, 28372845. doi: 10.1523/jneurosci.4121-06.2007

Na, E. S., Morris, M. J., Johnson, R. F., Beltz, T. G., and Johnson, A. K. (2007). The neural substrates of enhanced salt appetite after repeated sodium depletions. Brain Res. 1171, 104-110. doi: 10.1016/j.brainres.2007.07.033

Niimi, M., Sato, M., and Taminato, T. (2001). Neuropeptide Y in central control of feeding and interactions with orexin and leptin. Endocrine 14, 269-273. doi: 10. 1385/ENDO:14:2:269

Olds, J. (1958). Effects of hunger and male sex hormone on self-stimulation of the brain. J. Comp. Physiol. Psychol. 51, 320-324. doi: 10.1037/h0040783

Olds, J., and Milner, P. (1954). Positive reinforcement produced by electrical stimulation of septal area and other regions of rat brain. J. Comp. Physiol. Psychol. 47, 419-427. doi: 10.1037/h0058775

Peciña, S., and Berridge, K. C. (2000). Opioid site in nucleus accumbens shell mediates eating and hedonic 'liking' for food: map based on microinjection Fos plumes. Brain Res. 863, 71-86. doi: 10.1016/s0006-8993(00)02102-8

Petrovich, G. D., and Gallagher, M. (2007). Control of food consumption by learned cues: a forebrain-hypothalamic network. Physiol. Behav. 91, 397-403. doi: 10. 1016/j.physbeh.2007.04.014

Petrovich, G., Hobin, M., and Reppucci, C. (2012). Selective Fos induction in hypothalamic orexin/hypocretin, but not melanin-concentrating hormone neurons, by a learned food-cue that stimulates feeding in sated rats. Neuroscience 224, 70-80. doi: 10.1016/j.neuroscience.2012.08.036

Petrovich, G. D., Holland, P. C., and Gallagher, M. (2005). Amygdalar and prefrontal pathways to the lateral hypothalamus are activated by a learned cue that stimulates eating. J. Neurosci. 25, 8295-8302. doi: 10.1523/jneurosci.2480-05. 2005

Petrovich, G. D., Ross, C. A., Gallagher, M., and Holland, P. C. (2007). Learned contextual cue potentiates eating in rats. Physiol. Behav. 90, 362-367. doi: 10. 1016/j.physbeh.2006.09.031

Peyron, C., Tighe, D. K., van den Pol, A. N., de Lecea, L., Heller, H. C., Sutcliffe, J. G., et al. (1998). Neurons containing hypocretin (orexin) project to multiple neuronal systems. J. Neurosci. 18, 9996-10015.

Phillipson, O. (1979). Afferent projections to the ventral tegmental area of Tsai and interfascicular nucleus: a horseradish peroxidase study in the rat. J. Comp. Neurol. 187, 117-143. doi: 10.1002/cne.901870108

Robinson, M. J., and Berridge, K. C. (2013). Instant transformation of learned repulsion into motivational "wanting". Curr. Biol. 23, 282-289. doi: 10.1016/j. cub.2013.01.016

Roitman, M. F., Na, E., Anderson, G., Jones, T. A., and Bernstein, I. L. (2002). Induction of a salt appetite alters dendritic morphology in nucleus accumbens and sensitizes rats to amphetamine. J. Neurosci. 22, RC225-RC230.

Roitman, M. F., Schafe, G. E., Thiele, T. E., and Bernstein, I. L. (1997). Dopamine and sodium appetite: antagonists suppress sham drinking of $\mathrm{NaCl}$ solutions in the rat. Behav. Neurosci. 111, 606-611. doi: 10.1037//0735-7044.111. 3.606

Rolls, B. J., and Phillips, P. A. (1990). Aging and disturbances of thirst and fluid balance. Nutr. Rev. 48, 137-144. doi: 10.1111/j.1753-4887.1990.tb02915.x

Sakai, R. R., Fine, W. B., Epstein, A. N., and Frankmann, S. P. (1987). Salt appetite is enhanced by one prior episode of sodium depletion in the rat. Behav. Neurosci. 101, 724-731. doi: 10.1037//0735-7044.101.5.724

Sakai, R. R., Frankmann, S. P., Fine, W. B., and Epstein, A. N. (1989). Prior episodes of sodium depletion increase the need-free sodium intake of the rat. Behav. Neurosci. 103, 186-192. doi: 10.1037//0735-7044.103.1.186

Sakurai, T., Amemiya, A., Ishii, M., Matsuzaki, I., Chemelli, R. M., Tanaka, H., et al. (1998). Orexins and orexin receptors: a family of hypothalamic neuropeptides and $G$ protein-coupled receptors that regulate feeding behavior. Cell 92, 573 585. doi: 10.1016/s0092-8674(00)80949-6

Samson, W. K., Gosnell, B., Chang, J., Resch, Z. T., and Murphy, T. C. (1999). Cardiovascular regulatory actions of the hypocretins in brain. Brain Res. 831, 248-253. doi: 10.1016/s0006-8993(99)01457-2 
Schulkin, J. (1986). "The evolution and expression of salt appetite," in The Physiology of Thirst and Sodium Appetite, eds G. De Caro A. N. Epstein and M. Massi (New York: Plenum Press), 491-496).

Schwartz, M. W., Woods, S. C., Porte, D., Seeley, R. J., and Baskin, D. G. (2000). Central nervous system control of food intake. Nature 404, 661-671. doi: 10. 1038/35007534

Shepherd, J. D., and Bear, M. F. (2011). New views of Arc, a master regulator of synaptic plasticity. Nat. Neurosci. 14, 279-284. doi: 10.1038/nn. 2708

Smith, P. M., and Ferguson, A. V. (2014). Metabolic signaling to the central nervous system: routes across the blood brain barrier. Curr. Pharm. Des. 20, 1392-1399. doi: 10.2174/13816128113199990560

Spinazzi, R., Andreis, P. G., Rossi, G. P., and Nussdorfer, G. G. (2006). Orexins in the regulation of the hypothalamic-pituitary-adrenal axis. Pharmacol. Rev. 58, 46-57. doi: 10.1124/pr.58.1.4

Stellar, E. (1954). The physiology of motivation. Psychol. Rev. 61, 5-22. doi: 10. 1037/h0060347

Swanson, L., and Lind, R. (1986). Neural projections subserving the initiation of a specific motivated behavior in the rat: new projections from the subfornical organ. Brain Res. 379, 399-403. doi: 10.1016/0006-8993(86)90 799-7

Swanson, L., and Mogenson, G. (1981). Neural mechanisms for the functional coupling of autonomic, endocrine and somatomotor responses in adaptive behavior. Brain Res. 3, 1-34. doi: 10.1016/0165-0173(81)90 010-2

Swanson, L. W., Sanchez-Watts, G., and Watts, A. G. (2005). Comparison of melanin-concentrating hormone and hypocretin/orexin mRNA expression patterns in a new parceling scheme of the lateral hypothalamic zone. Neurosci. Lett. 387, 80-84. doi: 10.1016/j.neulet.2005.06.066

Teitelbaum, P., and Epstein, A. N. (1962). The lateral hypothalamic syndrome: recovery of feeding and drinking after lateral hypothalamic lesions. Psychol. Rev. 69, 74-90. doi: 10.1037/h0039285

Thompson, R. H., and Swanson, L. W. (2010). Hypothesis-driven structural connectivity analysis supports network over hierarchical model of brain architecture. Proc. Natl. Acad. Sci. U S A 107, 15235-15239. doi: 10.1073/pnas. 1009112107

Thorpe, A., and Kotz, C. (2005). Orexin A in the nucleus accumbens stimulates feeding and locomotor activity. Brain Res. 1050, 156-162. doi: 10.1016/j. brainres.2005.05.045

Toshinai, K., Date, Y., Murakami, N., Shimada, M., Mondal, M. S., Shimbara, T., et al. (2003). Ghrelin-induced food intake is mediated via the orexin pathway. Endocrinology 144, 1506-1512. doi: 10.1210/en.2002-220788
Tzingounis, A. V., and Nicoll, R. A. (2006). Arc/Arg3. 1: linking gene expression to synaptic plasticity and memory. Neuron 52, 403-407. doi: 10.1016/j.neuron. 2006.10.016

Valenstein, E. S., Cox, V. C., and Kakolewski, J. W. (1970). Reexamination of the role of the hypothalamus in motivation. Psychol. Rev. 77, 16-31. doi: 10. 1037/h0028581

van den Heuvel, J. K., Furman, K., Gumbs, M. C., Eggels, L., Opland, D. M., Land, B. B., et al. (2014). Neuropeptide Y activity in the nucleus accumbens modulates feeding behavior and neuronal activity. Biol. Psychiatry doi: 10.1016/j.biopsych. 2014.06.008. [Epub ahead of print].

Warren, J. L., Bacon, W. E., Harris, T., McBean, A. M., Foley, D. J., and Phillips, C. (1994). The burden and outcomes associated with dehydration among US elderly, 1991. Am. J. Public Health 84, 1265-1269. doi: 10.2105/ajph.84.8.1265

Wise, R. A. (1968). Hypothalamic motivational systems: fixed or plastic neural circuits? Science 162, 377-379. doi: 10.1126/science.162.3851.377

Wolf, G. (1964). Effect of dorsolateral hypothalamic lesions on sodium appetite elicited by desoxycorticosterone and by acute hyponatremia. J. Comp. Physiol. Psychol. 58, 396-402. doi: 10.1037/h0048232

Wolf, G., and Quartermain, D. (1967). Sodium chloride intake of adrenalectomized rats with lateral hypothalamic lesions. Am. J. Physiol. 212, 113-118.

Yi, C. X., van der Vliet, J., Dai, J., Yin, G., Ru, L., and Buijs, R. M. (2006). Ventromedial arcuate nucleus communicates peripheral metabolic information to the suprachiasmatic nucleus. Endocrinology 147, 283-294. doi: 10.1210/en. 2005-1051

Conflict of Interest Statement: The authors declare that the research was conducted in the absence of any commercial or financial relationships that could be construed as a potential conflict of interest.

Received: 13 June 2014; paper pending published: 08 September 2014; accepted: 13 October 2014; published online: 13 November 2014.

Citation: Hurley SW and Johnson AK (2014) The role of the lateral hypothalamus and orexin in ingestive behavior: a model for the translation of past experience and sensed deficits into motivated behaviors. Front. Syst. Neurosci. 8:216. doi: $10.3389 /$ fnsys.2014.00216

This article was submitted to the journal Frontiers in Systems Neuroscience.

Copyright $($ C) 2014 Hurley and Johnson. This is an open-access article distributed under the terms of the Creative Commons Attribution License (CC BY). The use, distribution and reproduction in other forums is permitted, provided the original author(s) or licensor are credited and that the original publication in this journal is cited, in accordance with accepted academic practice. No use, distribution or reproduction is permitted which does not comply with these terms. 